\title{
Laparoscopic cholecystectomy in situs inversus totalis
}

\author{
Erdem Kınacı, Ekrem Çakar, Savaş Bayrak, Mert Mahsuni Sevinç, \\ Şükrü Çolak, Hasan Ökmen, Hasan Bektaş \\ Department of General Surgery, University of Health Sciences, İstanbul Training and Research Hospital, İstanbul, Turkey
}

"Situs inversus totalis" (SIT) is a rare congenital anomaly related the whole organs in thorax and abdomen, in which location of all viscera is the mirror image of normal anatomy according to the sagittal plane. This extraordinary location of the viscera causes extraordinary surgical operations to be performed. According to the recently published literature, the number of reported cases related to laparoscopic cholecystectomy (LC) in patients with SIT has not reached to $30 .{ }^{[1]}$

Approximately 2 years ago, we reported a case of LC in a 55 years-old female patient with SIT, in $12^{\text {th }}$ (Turkish) National Congress of Endoscoic Laparoscopic Surgery. The patient was admitted to general surgery outpatient clinic with compliants of intermittant attacks of left upper quadrant pain and nausea with known history of SIT. In laboratory examination, there was no significant finding. SIT was reported again in ultrasonographic examination in addition to the findings of multiple milimetric gall stones. CT scan shows the general thoracal and abdominal anatomy of the patient. (Figure 1) The patient prepared for and underwent to elective LC. Four ports (10 mm just inferior to umblicus, $10 \mathrm{~mm}$ to epigastrium, two of $5 \mathrm{~mm}$ ports to subcostal area) were placed on abdomen as shown in Figure 2. The operation was in completely normal course except location of the organs. The operation time $75 \mathrm{~min}$ utes. The most challanging point of the dissection was the dissection of Calot Triangle and procurement of "critical view of safety" due to the left hand manipulations performed by right-handed surgeon. The postoperative period was uneventful and the patient was discharged in the first postoperative day.

LC in patients with SIT could be a challange for surgeons due to unfamiliar left handed dissection and unusual location of laparoscopic devices. We had also the same problems during surgery in our patient such as slowness, unfamiliar locations of devices and left-hand work. The operation time was 75 minutes, which was a little bit longer than previously reported data which was between 45 to 70 minutes $^{[1-3]}$ and our routine clinical practice. Locations of devices and left-hand work could be the causes of slowness in manupilations.

Regardless of anatomical situation, the most important complication of LC is biliary tract injury. ${ }^{[4]}$ Therefore, "critical view of safety" and essentials of safe LC should never be ignored, no matter what the situation is. ${ }^{[4]}$ Interestingly, there have been no published case of biliary injury during LC in patients with SIT, although many challenges have been reported in these extraordinary cases. Way and colleagues, in their study evaluating human related and cognitive psychological factors effecting iatrogenic biliary injuries, concluded that the misperception could not be a universal cause of biliary injury, and underlying cause of injury should be unique for each case. ${ }^{[5]}$ The absence of 


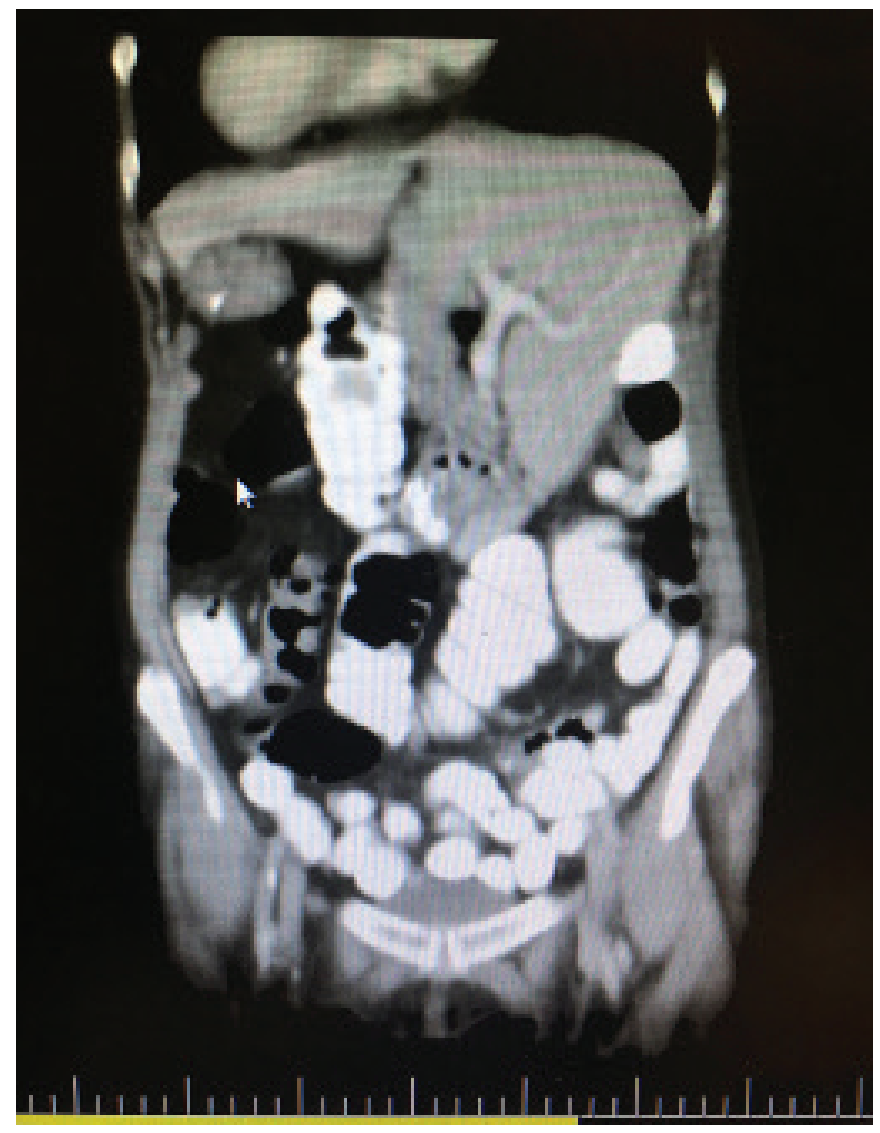

Figure 1. General thoracal and abdominal anatomoy of the patient on CT scan.

reported biliary injury in cases of LC in patients with SIT can be percieved as an evidence of these conclusions. The exceptionality of these cases may prevent an injury by referring the surgeon to be more careful. On the other hand, the low number of reported cases may be the reason of the absence of reported biliary injury. It does not seem to be possible to clarify this point of issue with the current data.

As a result, LC in patients with SIT seems to continue to attract the attention of the authors. However, the main theme of the articles to be written thereafter should have

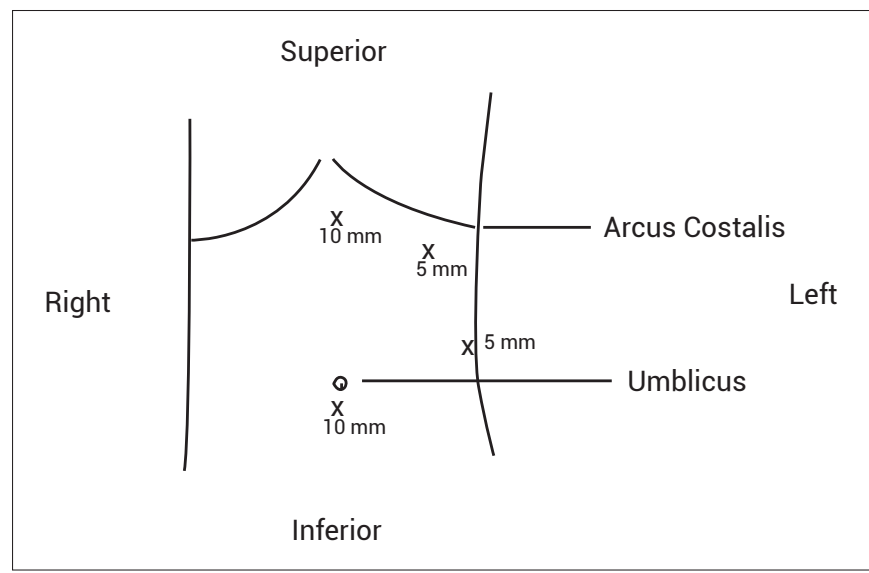

Figure 2. Locations of the trochars on the abdomen.

the messages related to prevent potential severe complications and the ways to ease this unusual manipulations, rather than the rarity of the such situation.

\section{References}

1. Alam A, Santra A. Laparoscopic cholecystectomy in a case of situs inversus totalis: a review of technical challenges and adaptations. Ann Hepatobiliary Pancreat Surg 2017;21:847. [CrossRef]

2. Fanshawe AEE, Qurashi K. Laparoscopic cholecystectomy for gallstone pancreatitis in a patient with situs inversus totalis. J Surg Case Rep 2017;2017:rjx003.

3. Rungsakulkij N, Tangtawee P. Fluorescence cholangiography during laparoscopic cholecystectomy in a patient with situs inversus totalis: a case report and literature review. BMC Surg 2017;17:43. [CrossRef]

4. Abbasoğlu O, Tekant Y, Alper A, Aydın Ü, Balık A, Bostancı B, et al. Prevention and acute management of biliary injuries during laparoscopic cholecystectomy: Expert consensus statement. Ulus Cerrahi Derg 2016;32:300-5. [CrossRef]

5. Way LW, Stewart L, Gantert W, Liu K, Lee CM, Whang K, et al. Causes and prevention of laparoscopic bile duct injuries: analysis of 252 cases from a human factors and cognitive psychology perspective. Ann Surg 2003;237:460-9. [CrossRef] 